Article

\title{
Single Grain Boundary Modeling and Design of Microcrystalline Si Solar Cells
}

\author{
Chu-Hsuan Lin *, Wen-Tzu Hsu and Cheng-Hung Tai \\ Department of Opto-Electronic Engineering, National Dong Hwa University, Shoufeng, \\ Hualien 97401, Taiwan; E-Mails: m9925003@ems.ndhu.edu.tw (W.-T.H.); \\ m9724010@ems.ndhu.edu.tw (C.-H.T.) \\ * Author to whom correspondence should be addressed; E-Mail: chlin0109@mail.ndhu.edu.tw; \\ Tel.: +886-3-8634188; Fax: +886-3-8634180.
}

Received: 23 October 2012; in revised form: 26 December 2012 / Accepted: 15 January 2013 / Published: 21 January 2013

\begin{abstract}
For photovoltaic applications, microcrystalline silicon has a lot of advantages, such as the ability to absorb the near-infrared part of the solar spectrum. However, there are many dangling bonds at the grain boundary in microcrystalline Si. These dangling bonds would lead to the recombination of photo-generated carriers and decrease the conversion efficiency. Therefore, we included the grain boundary in the numerical study in order to simulate a microcrystalline Si solar cell accurately, designing new three-terminal microcrystalline Si solar cells. The 3- $\mu$ m-thick three-terminal cell achieved a conversion efficiency of $10.8 \%$, while the efficiency of a typical two-terminal cell is $9.7 \%$. The three-terminal structure increased the $\mathrm{J}_{\mathrm{SC}}$ but decreased the $\mathrm{V}_{\mathrm{OC}}$, and such phenomena are discussed. High-efficiency and low-cost Si-based thin film solar cells can now be designed based on the information provided in this paper.
\end{abstract}

Keywords: microcrystalline silicon; grain boundary; three-terminal cell

\section{Introduction}

Low cost Si-based materials, including microcrystalline silicon ( $\mu \mathrm{c}-\mathrm{Si})$ and amorphous silicon (a-Si), are promising for use in photovoltaic applications. The $\mu \mathrm{c}-\mathrm{Si}$ solar cell has a slight light-induced degradation so that it can stably maintain efficiency compared to the a-Si solar cell [1]. Therefore, $\mu \mathrm{c}-\mathrm{Si}$ is a key material among several common materials for thin film solar cells. Plasma 
enhanced chemical vapor deposition (PECVD) and very high frequency plasma-enhanced chemical vapor deposition (VHF PECVD) are usually used to prepare $\mu \mathrm{c}-\mathrm{Si}$ thin film solar cells [2,3]. In addition, hot wire chemical vapor deposition (HWCVD) and photochemical vapor deposition (photo-CVD) can also be used to deposit $\mu \mathrm{c}-\mathrm{Si}$ film at a low fabrication temperature [4-6]. The low fabrication temperature is suitable for substrates of low cost, low melting points and with a low thermal budget. Generally, the fabrication based on HWCVD can lead to a high deposition rate and high open circuit voltage $\left(\mathrm{V}_{\mathrm{OC}}\right)$ [7]. For the near-infrared part of the solar spectrum, the narrow band gap of the $\mu \mathrm{c}-\mathrm{Si}$ contributes to high quantum efficiency (QE).

Although $\mu \mathrm{c}-\mathrm{Si}$ offers a lot of advantages for photovoltaic applications, the $\mu \mathrm{c}-\mathrm{Si}$ film has dangling bonds at the grain boundary (GB) [8]. The conversion efficiency of solar cells is limited by recombination of photo-generated carriers at dangling bonds of the grain boundary [9]. In this paper, we therefore included the grain boundary in the numerical study. In addition, we propose a new three-terminal $\mu \mathrm{c}-\mathrm{Si}$ structure to suppress such recombination. We investigated the two-terminal and the three-terminal $\mu \mathrm{c}$-Si solar cells with the same material parameters and device thicknesses, utilizing the simulation tool, Sentaurus TCAD. In the tool, a device was discretized into a finite number of nodes, and material parameters - such as doping concentration-were assigned to each node. All quantities for any point between these nodes could be obtained by interpolation. A fully coupled Poisson and electron/hole continuity equations were self-consistent solved. The optical model for optical generation was raytracing, where a plane wave was partitioned into one-dimensional rays of light. The refractive index, $\mathrm{n}$, and extinction coefficient, $\mathrm{k}$, as a function of the wavelength for different materials were included in advance. The absorption coefficient $\alpha$ was calculated from the formula $\alpha=4 \pi \mathrm{k} / \lambda$, where $\lambda$ was the wavelength of light. The original AM $1.5 \mathrm{G}$ solar spectrum was taken from [10], with wavelengths ranging from $320 \mathrm{~nm}$ to $2280 \mathrm{~nm}$ and a sampling interval of $40 \mathrm{~nm}$. The $\mu \mathrm{c}-\mathrm{Si}$ was usually deposited on glass with rough (textured) transparent conducting oxide (TCO) for the superstrate cell structure. In order to consider the reflection or scattering of light [11] at air/glass, glass/TCO, TCO/ $\mu \mathrm{c}-\mathrm{Si}$ interfaces, an optical simulation tool, RSOFT was used. First, the reflection (R) of air/glass/TCO/Si with different texture periods ranging from 0.2 to $1 \mu \mathrm{m}$ was calculated and averaged. The AM 1.5G spectrum was then weighted by (1-average $\mathrm{R})$ as the input spectrum for Sentaurus to include the reflection or scattering effects.

\section{Device Structure}

In the numerical study, the $3-\mu \mathrm{m}$-thick $\mathrm{p} / \mathrm{i} / \mathrm{n}$ two terminal and $\mathrm{p} / \mathrm{i} / \mathrm{n} / \mathrm{n} / \mathrm{i} / \mathrm{p}$ three-terminal $\mu \mathrm{c}-\mathrm{Si}$ solar cells have been investigated. The doping concentrations and the device structures of the two-terminal (control) and the three-terminal $\mu \mathrm{c}-\mathrm{Si}$ solar cells are shown in Figure 1. Light of AM1.5G solar spectrum is irradiated perpendicularly to the cell junction from the top side. Some material parameters used in this study were listed in Table 1. Both the control cells and the three-terminal cells have a thickness of $3 \mu \mathrm{m}$ and all of the n-layers and p-layers were $0.02 \mu \mathrm{m}$. For both cells, the area of illumination is the same. Moreover, doping concentrations of n-layers, i-layers and p-layers are identical for both cells. The unintentionally doped i-layer is assumed to be $n$ type with a concentration of $10^{15} \mathrm{~cm}^{-3}$. Since the practical $\mu \mathrm{c}$-Si solar cells suffer from the recombination of photo-generated 
carriers at the grain boundaries [12], the grain boundaries (GBs) are set in the middle of the intrinsic layers as shown in Figure 1.

Table 1. Parameters used for microcrystalline silicon solar cells in this numerical study.

\begin{tabular}{ccc}
\hline Input parameters & $\boldsymbol{\mu c - S i}$ & GB interface \\
\hline Carriers mobility $\left(\mathrm{cm}^{2} / \mathrm{Vs}\right)$ & $40(\mathrm{e}) / 10(\mathrm{~h})$ & N/A \\
Peak of band-tail density of states & $10^{19}\left(\mathrm{~cm}^{-3}\right)$ & $10^{12}\left(\mathrm{~cm}^{-2}\right)$ \\
Peak of Gaussian density of states & $10^{14}\left(\mathrm{~cm}^{-3}\right)$ & $10^{10}\left(\mathrm{~cm}^{-2}\right)$ \\
Conduction band tail width $(\mathrm{eV})$ & 0.027 & 0.027 \\
Valence band tail width $(\mathrm{eV})$ & 0.045 & 0.045 \\
\hline
\end{tabular}

Figure 1. (a) The schematic structure of the typical two-terminal; and (b) the three-terminal $\mu \mathrm{c}-\mathrm{Si}$ solar cells. The unintentionally doped i-layer is assumed to be n-type as observed in the experimental data.

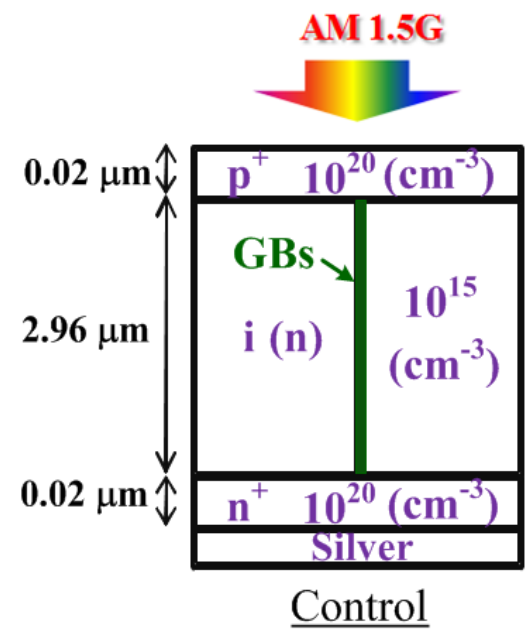

(a)

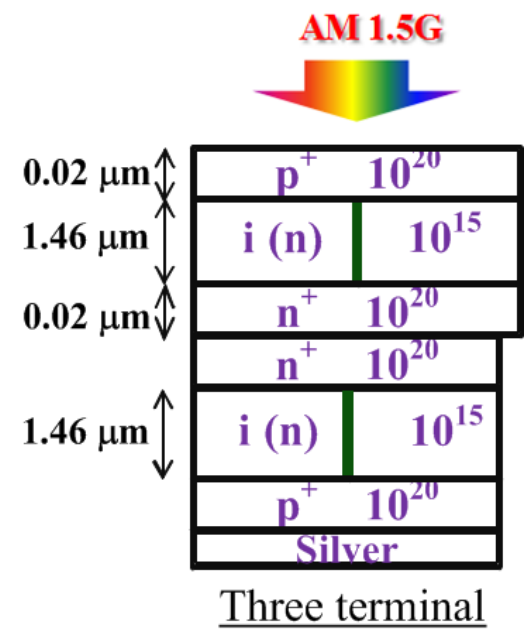

(b)

The reported $\mu \mathrm{c}-\mathrm{Si}$ solar cells have a crystallinity (Xc) of about $60 \%$ [3]. The crystallinity of $60 \%$ from the Raman measurement corresponds to the volume fraction of $\sim 90 \%$ [13]. Hence, the refractive index and extinction coefficient values of $\mu \mathrm{c}-\mathrm{Si}$ in this study are calculated from $90 \% \mathrm{c}-\mathrm{Si}$ and $10 \%$ a-Si. Particulars of the grain boundary between the crystalline columns can be found in [14]. The TEM in [14] supports this idea. In [8], the assumption of the grain boundary region within a $\mu \mathrm{c}-\mathrm{Si}$ layer achieves an accurate simulation for the experimental data. The conduction band/valence band tail states and two Gaussian dangling bond states have been set as the density of state in the grain boundary in [8]. Hence, we constructed our model of the control two-terminal cell based on such a concept, and the parameters for density of state are shown in Table 1 . We can therefore obtain a simulation result close to the practical two-terminal cell. Furthermore, we could then show the influence of a three-terminal structure for the material of $\mu \mathrm{c}-\mathrm{Si}$.

The control cell is a typical pin solar cell. The three-terminal cell consists of two pin subcells connected in parallel, and each subcell is structurally the same as the control cell. The depletion region of the pin structure results in the built-in potential and helps the separation of photo-generated carriers [15]. For the control cell, the photo-generated holes and electrons would drift to the p-layer and n-layer, respectively. On the other hand, in the three-terminal cell, the photo-generated holes in the 
top subcell would drift to the top p-layer while photo-generated holes of the bottom subcell would drift to the bottom p-layer. Photo-generated electrons in the three-terminal cell would always drift to the n-layers between the subcells. Hence, unlike the tandem cell in serial configuration, the currents do not need to match for the three-terminal cell.

\section{Results and Discussion}

For the control cell, the p-layer is connected with the outer circuit by the top contact and acts as the anode, and the n-layer is connected with the outer circuit by the bottom contact and acts as the cathode. For the three-terminal cell, the two p-layers are joined and connected to the outer circuit, and act as the anode. The n-layer is connected with the outer circuit via the middle contact and acts as the cathode.

The simulated J-V curves of the two-terminal cell and the three-terminal cell are shown in Figure 2. For the two-terminal control $\mu \mathrm{c}-\mathrm{Si}$ solar cell, the efficiency was $9.7 \%$, the $\mathrm{V}_{\mathrm{OC}}$ was $0.530 \mathrm{~V}$, and the $\mathrm{J}_{\mathrm{SC}}$ was $24.8 \mathrm{~mA} / \mathrm{cm}^{2}$. Meanwhile, the three-terminal cell could achieve a conversion efficiency of $10.8 \%$, a $\mathrm{V}_{\mathrm{OC}}$ of $0.523 \mathrm{~V}$, and a $\mathrm{J}_{\mathrm{SC}}$ of $26.8 \mathrm{~mA} / \mathrm{cm}^{2}$. The three-terminal cell had a better efficiency as compared with the control cell.

Figure 2. The J-V curve of the typical two-terminal (control) and the three-terminal $\mu \mathrm{c}-\mathrm{Si}$ solar cells. The efficiency of the three-terminal cell is $10.8 \%$, and the efficiency of the control cell is $9.7 \%$.

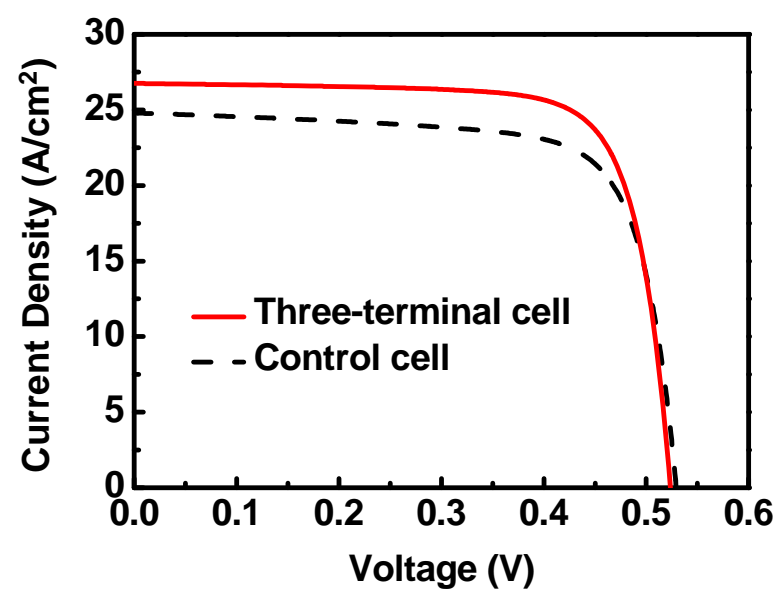

For comparison, the performance of practical two-terminal cells demonstrated in [16] is described as following. A two-terminal $\mu \mathrm{c}$-Si solar cell fabricated by HWCVD had an efficiency of $9.4 \%$, a $\mathrm{V}_{\mathrm{OC}}$ of $0.58 \mathrm{~V}$, and a $\mathrm{J}_{\mathrm{SC}}$ of $23.3 \mathrm{~mA} / \mathrm{cm}^{2}$. On the other hand, the same efficiency of $9.4 \%$, a $\mathrm{V}_{\mathrm{OC}}$ of $0.53 \mathrm{~V}$, and a $\mathrm{J}_{\mathrm{SC}}$ of $25.1 \mathrm{~mA} / \mathrm{cm}^{2}$ could be achieved when it was fabricated by PECVD. Our simulation results are close to these reported data.

Figure 3 shows the $0-\mathrm{V}$ band diagrams of the control cell and the three-terminal cell. There are two pin structures in the three-terminal cell. Meanwhile, there is only one pin structure in the control cell. The benefit of two pin structures in the three-terminal structure is described as follows. 
Figure 3. The band diagrams of the three-terminal cell and the control cell. The photo-generated electrons and holes drift to the n-layers and p-layers, respectively.

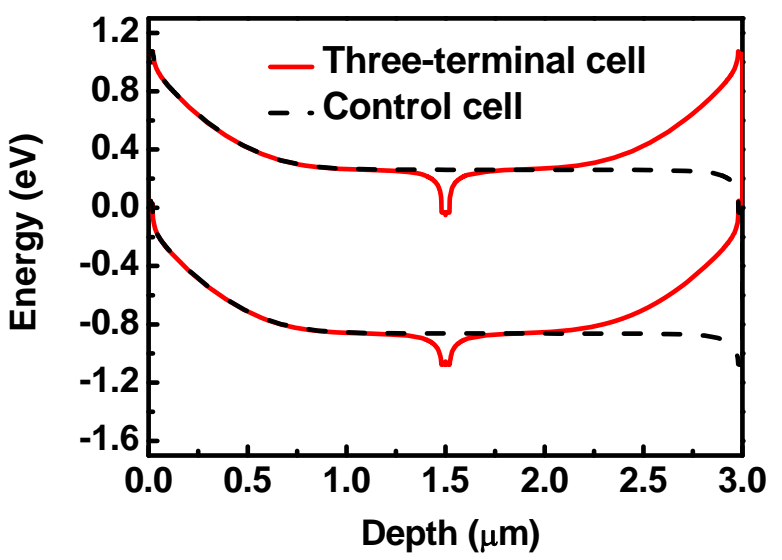

The magnitude of the electric field as a function of the depth is shown in Figure 4. The electric field is widely boosted for the $\mathrm{p} / \mathrm{i}$ junction, because the $\mathrm{i}$-layer is assumed to be of an unintentionally doped $\mathrm{n}$-type material. There are two $\mathrm{p} / \mathrm{i}$ junctions for the three-terminal cell; meanwhile, there is only one $\mathrm{p} / \mathrm{i}$ junction for the control cell. Hence, the electric field at the depths of both $0 \sim 1.0 \mu \mathrm{m}$ and $2.0 \sim 3.0 \mu \mathrm{m}$ is boosted for the three-terminal cell. However, the electric field is only boosted at a depth of $0 \sim 1.0 \mu \mathrm{m}$ in the control cell. Compared to the control cell, the electric-field boosted region is wider in the three-terminal cell. In the electric-field boosted region, the photo-generated electron-hole pairs can be easily separated without recombination. In addition, there are two high-field $\mathrm{i} / \mathrm{n}$ regions at the depths of 1.4 1.5 $\mu \mathrm{m}$ and 1.5 1.6 $\mu \mathrm{m}$ for the three-terminal cell, which is also superior to one high-field $\mathrm{i} / \mathrm{n}$ region at the depth of $2.9 \sim 3.0 \mu \mathrm{m}$ of the control cell. The enhancement of the efficiency of the three-terminal cell is achieved by reducing the recombination rate of the photo-generated carriers via a larger average electric field.

Figure 4. The magnitude of the electric field as a function of the depth. The electric field is widely boosted for the $\mathrm{p} / \mathrm{i}$ junction.

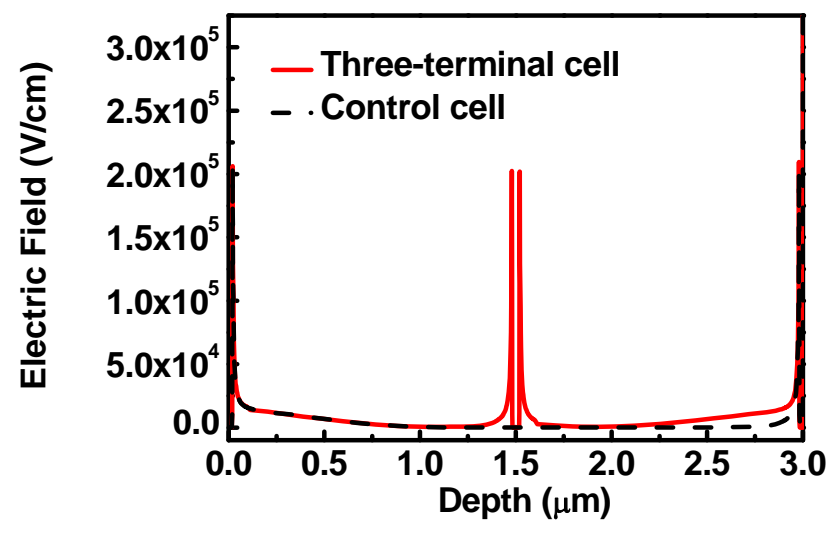

Figure 5 shows the recombination rate of the three-terminal cell and the control cell. As mentioned above, the larger average electric field in the three-terminal cell results in a smaller recombination rate. The three-terminal cell has a lower recombination rate than the control cell, and thus the efficiency of the three-terminal cell could be higher than the control cell. 
Figure 5. The recombination rate of the three-terminal cell and the two-terminal (control) cell. The three-terminal cell has a lower recombination rate than the control cell.

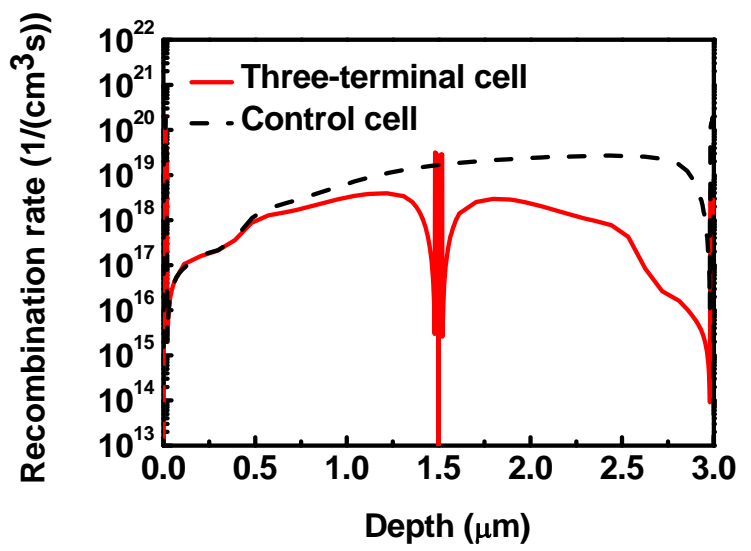

In [17], when the three-terminal structure was applied to a-Si, both the $\mathrm{J}_{\mathrm{SC}}$ and $\mathrm{V}_{\mathrm{OC}}$ increased compared to the typical two-terminal cell. However, for $\mu \mathrm{c}-\mathrm{Si}$, the three-terminal structure only increased the $\mathrm{J}_{\mathrm{SC}}$ but decreased the $\mathrm{V}_{\mathrm{OC}}$. Since the subcells in the three-terminal cells are in parallel, the final $\mathrm{J}_{\mathrm{SC}}$ is obtained with summation but the final $\mathrm{V}_{\mathrm{OC}}$ would be between the $\mathrm{V}_{\mathrm{OC}}$ of two subcells. It should be noted that $\mathrm{V}_{\mathrm{OC}}$ would decrease as the thickness of the active layer increases especially for highly defective materials. Hence, for the a-Si, the top subcell of the three terminal cell with a half thickness as compared with the control two-terminal cell, could have an obviously higher $\mathrm{V}_{\mathrm{OC}}$. The final $V_{O C}$, which would be between the $V_{O C}$ of the top subcell and the bottom subcell, of the three-terminal a-Si cell, could have larger $\mathrm{V}_{\mathrm{OC}}$ than that of the two-terminal a-Si cell. On the other hand, the $\mathrm{V}_{\mathrm{OC}}$ of $\mu \mathrm{c}-\mathrm{Si}$ is less sensitive to the thickness due to higher quality in the bulk. The $\mathrm{V}_{\mathrm{OC}}$ of the top subcell of the three-terminal $\mu \mathrm{c}$-Si cell would not be obviously larger than that of the control. The bottom subcell has an even smaller $\mathrm{V}_{\mathrm{OC}}$ due to insufficient absorption. Therefore, the final $\mathrm{V}_{\mathrm{OC}}$ of the three-terminal $\mu \mathrm{c}-\mathrm{Si}$ cell becomes smaller than the $\mathrm{V}_{\mathrm{OC}}$ of the two-terminal $\mu \mathrm{c}-\mathrm{Si}$ cell. The differing results between a-Si and $\mu \mathrm{c}-\mathrm{Si}$ cases can provide insight into their material properties, and we may apply this information in order to design better structures in the future.

\section{Conclusions}

We included grain boundaries in the simulation of $\mu \mathrm{c}-\mathrm{Si}$ solar cells. A new structure, the three-terminal $\mu \mathrm{c}-\mathrm{Si}$ solar cell, was designed and simulated. The 3- $\mu \mathrm{m}$-thick three-terminal $\mu \mathrm{c}-\mathrm{Si}$ solar cell achieved an efficiency of $10.8 \%$. The three-terminal structure appears to be promising for high efficiency photovoltaic applications by increasing the average electric field.

\section{Acknowledgments}

The author is grateful to the National Center for High-performance Computing for computer time and facilities (Sentaurus TCAD). This work is supported by the National Science Council of R.O.C. under contract No. 101-2221-E-259-023-MY3. 


\section{References}

1. Antonio, L.; Steven, H. Handbook of Photovoltaic Science and Engineering; John Wiley and Sons Inc.: Hoboken, NJ, USA, 2003; pp. 551-552.

2. Matsui, T.; Matsuda, A.; Kondo, M. High-rate microcrystalline silicon deposition for p-i-n junction solar cells. Sol. Energy Mater. Solar Cells 2006, 90, 3199-3204.

3. Mai, Y.; Klein, S.; Carius, R.; Wolff, J.; Lambertz, A.; Finger, F.; Geng, X. Microcrystalline silicon solar cells deposited at high rates. J. Appl. Phys. 2005, 97, 114913:1-114913:12.

4. Stolk, R.L.; Li, H.; Franken, R.H.; Schüttauf, J.W.A.; van der Werf, C.H.M.; Rath, J.K.; Sch, R.E.I. Improvement of the efficiency of triple junction n-i-p solar cells with hot-wire CVD proto- and microcrystalline silicon absorber layers. Thin Solid Films 2008, 516, 736-739.

5. Ide, Y.; Saito, YJ.; Yamada, A.; Konagai, M. Intrinsic microcrystalline silicon thin films prepared by hot-wire cell method and their application to solar cells. Jpn. J. Appl. Phys. 2004, 43, 7953-7959.

6. Hiza, S.; Konagai, M.; Yamada, A. Low-temperature deposition of hydrogenated microcrystalline silicon thin films by photochemical vapor deposition technique and their application to thin film solar cells. Jpn. J. Appl. Phys. 2007, 46, 1427-1431.

7. Mai, Y.; Klein1, S.; Carius1, R.; Stiebig, H.; Geng, X.; Finger, F. Open circuit voltage improvement of high-deposition-rate microcrystalline silicon solar cells by hot wire interface layers. Appl. Phys. Lett. 2005, 87, 073503:1-073503:3.

8. Chang, S.T.; Tang, M.; He, R.Y.; Wang, W.-C.; Pei, Z.; Kung, C.-Y. TCAD simulation of hydrogenated amorphous silicon-carbon/microcrystalline silicon/hydrogenated amorphous silicon-germanium PIN solar cells. Thin Solid Films 2010, 518, S250-S254.

9. Takahashi, T. Photoassisted kelvin probe force microscopy on multicrystalline Si solar cell materials. Jpn. J. Appl. Phys. 2011, 50, 08LA05:1-08LA05:8.

10. Antonio, L.; Steven, H. Handbook of Photovoltaic Science and Engineering; John Wiley and Sons Inc.: Hoboken, NJ, USA, 2003; p. 704.

11. Moharam, M.G.; Gaylord, T.K. Diffraction analysis of dielectric surface-relief gratings. J. Opt. Soc. Am. 1982, 72, 1385-1392.

12. Takakura, H.; Hamakawa, Y. Device simulation and modeling of microcrystalline silicon solar cells. Sol. Energy Mater. Sol. Cells 2002, 74, 479-487.

13. Siebke, F.; Yata, S.; Hishikawa, Y.; Tanaka, M. Correlation between structure and optoelectronic properties of undoped microcrystalline silicon. J. Non-Cryst. Solids 1998, 227-230, 977-981.

14. Vetterl, O.; Finger, F.; Carius, R.; Hapke, P.; Houben, L.; Kluth, O.; Lambertz, A.; Mück, A.; Rech, B.; Wagner, H. Intrinsic microcrystalline silicon: A new material for photovoltaics. Sol. Energy Mater. Sol. Cells 2000, 62, 97-108.

15. Lee, C.H.; Shin, M.; Lim, M.H.; Seo, J-Y.; Lee, J-E.; Lee, H-Y.; Kim, B-J.; Choi, D. Material properties of microcrystalline silicon for solar cell application. Sol. Energy Mater. Sol. Cells 2011, 95, 207-210. 
16. Klein, S.; Repmann, T.; Brammer, T. Microcrystalline silicon films and solar cells deposited by PECVD and HWCVD. Sol. Energy 2004, 77, 893-908.

17. Tai, C.H.; Lin, C.H.; Wang, C.M.; Lin, C.C. Three-terminal amorphous silicon solar cells. Int. J. Photoenergy 2011, 2011, 813093:1-813093:5.

(C) 2013 by the authors; licensee MDPI, Basel, Switzerland. This article is an open access article distributed under the terms and conditions of the Creative Commons Attribution license (http://creativecommons.org/licenses/by/3.0/). 